Article

\title{
Green Synthesized Palladium Coated Titanium Nanotube Arrays for Simultaneous Azo-Dye Degradation and Hydrogen Production
}

\author{
Yuan-Chung Lin ${ }^{1}$, Chia-Hung Chen ${ }^{1}$, Kang-Shin Chen ${ }^{1}$, Yen-Ping Peng ${ }^{1, *}$, \\ Yung-Chang Lin ${ }^{2,3,4, *}$, Shih-Wei Huang ${ }^{2,3,4}$, Chien-Er Huang ${ }^{3,4}$, Hsiao-Wu Lai 5 \\ and Hsing-Wang $\mathrm{Li}^{6}$ \\ 1 Institute of Environmental Engineering, National Sun Yat-sen University, Kaoshiung 804, Taiwan; \\ yclin@faculty.nsysu.edu.tw (Y.-C.L.); w102007635@gmail.com (C.-H.C.); shin@mail.nsysu.edu.tw (K.-S.C.) \\ 2 Department of Electrical Engineering, Cheng Shiu University, Kaoshiung 804, Taiwan; \\ envhero@gcloud.csu.edu.tw \\ 3 Center for Environmental Toxin and Emerging Contaminant Research, Cheng Shiu University, \\ Kaoshiung 804, Taiwan; k1668@gcloud.csu.edu.tw \\ 4 Super Micro Research and Technology Center, Cheng Shiu University, Kaoshiung 804, Taiwan \\ 5 Department of Chemical and Materials Engineering, Southern Taiwan University of Science and Technology, \\ Tainan 710, Taiwan; swlai@stust.edu.tw \\ 6 New Materials R\&D Department, China Steel Corporation, Kaoshiung 812, Taiwan; leestanly@yahoo.com.tw \\ * Correspondence: yppeng@mail.nsysu.edu.tw (Y.-P.P.); yclin@gcloud.csu.edu.tw (Y.-C.L.); \\ Tel.: +886-7-5252000 (ext. 4422) (Y.-P.P.); +886-7-7358800 (ext. 3432) (Y.-C.L.); \\ Fax: +886-7-5254449 (Y.-P.P.); +886-7-7332204 (Y.-C.L.)
}

Received: 24 September 2020; Accepted: 11 November 2020; Published: 16 November 2020

\begin{abstract}
In this study, electrodes of titanium dioxide nanotube arrays (TNAs) were successfully synthesized by applying the anodic oxidation etching method, as well as the use of green synthetic technology to add reducing agents of tea or coffee to reduce metal palladium from palladium chloride. Synthesis of palladium modified TNAs (Pd/TNAs) was conducted by the microwave hydrothermal method after the metal palladium was reduced. In order to identify the surface structure, light absorption and elemental composition, TNAs and Pd/TNAs were characterized by X-ray photoelectron spectroscopy (XPS), and X-ray diffraction (XRD). Furthermore, to test the photocurrent density, electron resistance, and hydroxyl radicals by I-t plot, electrochemistry impedance spectroscopy (EIS), and electron paramagnetic resonance (EPR) were investigated. The photocurrent $\left(4.0 \mathrm{~mA} / \mathrm{cm}^{2}\right)$ of $\mathrm{Pd} / \mathrm{TNAs}-\mathrm{C}$ (using coffee as the reducing agent) at $+1.0 \mathrm{~V}$ (vs. $\mathrm{Ag} / \mathrm{AgCl}$ ) was higher than that of the pure TNAs $\left(1.5 \mathrm{~mA} / \mathrm{cm}^{2}\right)$, illustrating that $\mathrm{Pd} / \mathrm{TNAs}-\mathrm{C}$ can effectively separate photogenerated electrons and holes. Pd/TNAs is a favorable material as a photoanode for the photoelectrochemical (PEC) removal of organic pollutants in wastewater.
\end{abstract}

Keywords: titanium dioxide nanotube arrays; photoelectrochemical system; palladium; green synthesis

\section{Introduction}

Chemical oxidation methods such as Fenton, ozone, hydrogen peroxide and chlorine oxidation are common used for the degradation of organic pollutants [1-3]. However, the oxidation efficiency may be low for compounds with benzene rings. To completely degrade persistent organic compounds, huge amounts of oxidation chemical are needed. The Fenton method applies $\mathrm{Fe}^{2+}$ as a catalyst to react with $\mathrm{H}_{2} \mathrm{O}_{2}$ to form hydroxyl radicals $(\cdot \mathrm{OH})$ and oxidize organic compounds, but it is accompanied with sludge, which leads to another environmental problem. 
Catalytic oxidation using $\mathrm{TiO}_{2}$ is an emerging and promising method to remove organic pollutants in water. Compared with other semiconductors, $\mathrm{TiO}_{2}$ has the advantages of non-toxicity, high stability, and strong oxidation ability. Recently, $\mathrm{TiO}_{2}$ has been used in many different types of applications such as photocatalytic degradation [4], $\mathrm{CO}_{2}$ reduction [5], solar cells [6-8], biomedical science [9], supercapacitors [10] and so on. Since Fujishima and Honda [11,12] first discovered the photoelectrochemical ability of $\mathrm{TiO}_{2}$, various types of $\mathrm{TiO}_{2}$ have been studied over the subsequent decades. Among them, titanium dioxide nanotube arrays (TNAs) are practical owing to their film structure, which is easy to reuse and recycle. Furthermore, TNAs can be applied as photo-anodes to conduct photoelectrochemical (PEC) experiments. The PEC system has demonstrated the ability to reduce the recombination of photo-generated holes and electrons, and, therefore, to enhance the oxidation ability of TNAs [1,13]. The absorption edge of $\mathrm{TiO}_{2}$ is about $380-400 \mathrm{~nm}$, depending on its allotropic crystalline phase, e.g., direct bandgap of $3.0 \mathrm{eV}$ for rutile [14], indirect bandgap of $3.2 \mathrm{eV}$ for anatase [15], and indirect bandgap of $3.4 \mathrm{eV}$ for brookite Pure [16]. TNAs have a similar light utilization region to $\mathrm{TiO}_{2} \mathrm{NPs}$ (nano-particles), i.e., 300-320 nm, which can only be excited by UV-light. Studies have attempted to solve the limitation of the light response of TNAs. Metals, non-metals, and metal oxides have been employed to modify TNAs. Peng et al. (2017) applied carbon and nitrogen to modify TNAs and found that this approach is useful to degrade perfluorooctanoic acid (PFOA). Sun et al. (2016) employed $\mathrm{Cu}_{2} \mathrm{O}$ to modify TNAs to form a p-n junction in $\mathrm{Cu}_{2} \mathrm{O} / \mathrm{TNAs}$. The results indicated that $\mathrm{Cu}_{2} \mathrm{O} / \mathrm{TNAs}$ can PEC oxidize Ibuprofen effectively. Among noble metals, palladium $(\mathrm{Pd})$ is the cheapest and the most commonly used for co-catalysis with $\mathrm{TiO}_{2}$. Ye et al. (2012) indicated that TNAs modified by palladium quantum dots exhibit significantly efficient photoelectrocatalytic hydrogen generation. Photo-generated electrons can be easily transferred from $\mathrm{TiO}_{2}$ to $\mathrm{Pd}$ particles deposited on the surface of $\mathrm{TiO}_{2}$, owing to the fact that the Fermi level of $\mathrm{Pd}$ is lower than $\mathrm{TiO}_{2}$, thereby greatly reducing the recombination of photo-generated electron-holes and leading to effective charge separation and increased photocatalysis reactions [17]. In addition to TNAs, Pd decorated $\mathrm{TiO}_{2}$ nanofibers $\left(\mathrm{TiO}_{2}-\mathrm{Pd} 300 \mathrm{NFs}\right)$ have proven to be an effective photocatalyst due to the formation of nano-sized Schottyky interfaces between $\mathrm{TiO}_{2}$ and nano-Pd particles [18].

The above studies show good examples of using TNAs for modification. However, these methods are either energy consuming or require chemicals that may cause other environmental problems. In recent years, the green synthesis of metal nanomaterials has attracted widespread attention. According to Anatas (1999), the definition of green chemistry refers to the design, development and implementation of chemical products and processes to reduce or eliminate the use and generation of substances hazardous to human health and the environment [19]. Palladium nanoparticles have been green synthesized with the help of aloe vera gel [20], extracts of Aspalathus Linearis [21], tea [22,23], coffee $[22,24]$, etc. In this study, coffee and green tea was employed to green-synthesize palladium modified TNAs (Pd/TNAs) for the first time.

In Taiwan, the heavy use of organic compounds by humans has caused severe environmental damage. Most organic compounds are toxic and will cause harm to the environment and organisms once discharged without proper treatment. Discharge of dyeing wastewater into rivers can cause chromaticity problems, and some dyes can even cause cancer. In this study, methyl orange was selected as a target compound for the PEC oxidation experiment.

\section{Results and Discussion}

\subsection{Physical and Chemical Properties of TNAs and Pd/TNAs}

The microstructure of the surface of the as-synthesized material was observed by SEM. From Figure 1a, it can be seen that TNAs were successfully fabricated by the anodization method. The average diameter of the nanotube columns is $300-400 \mathrm{~nm}$. The length of the nano tube is about 2-3 $\mu \mathrm{m}$, according to the cross-sectional view shown in Figure 1b. Figure 1c shows the SEM image of $\mathrm{Pd} / \mathrm{TNAs}$ prepared by the microwave hydrothermal method. It can be seen that the Pd NPs were 
deposited on the surface of TNAs. Furthermore, Figure 1d and e shows the SEM images of Pd/TNAs-C and Pd/TNAs-G, which were synthesized by using coffee and green tea as reductants. The obvious Pd NPs were deposited on the surface of the tubular structure of TNAs with a size of about $10 \mathrm{~nm}$. Figure S1 shows the SEM mapping of Pd/TNAs-C that illustrates the existence of Pd NPs on the TNAs. The at $\%$ of Pd was $1.49 \%$, as determined from the results of SEM EDS analysis (Table S1). The results of SEM demonstrate that Pd NPs were successfully deposited in the TNAs and this was enhanced when using coffee and green tea as reductants.
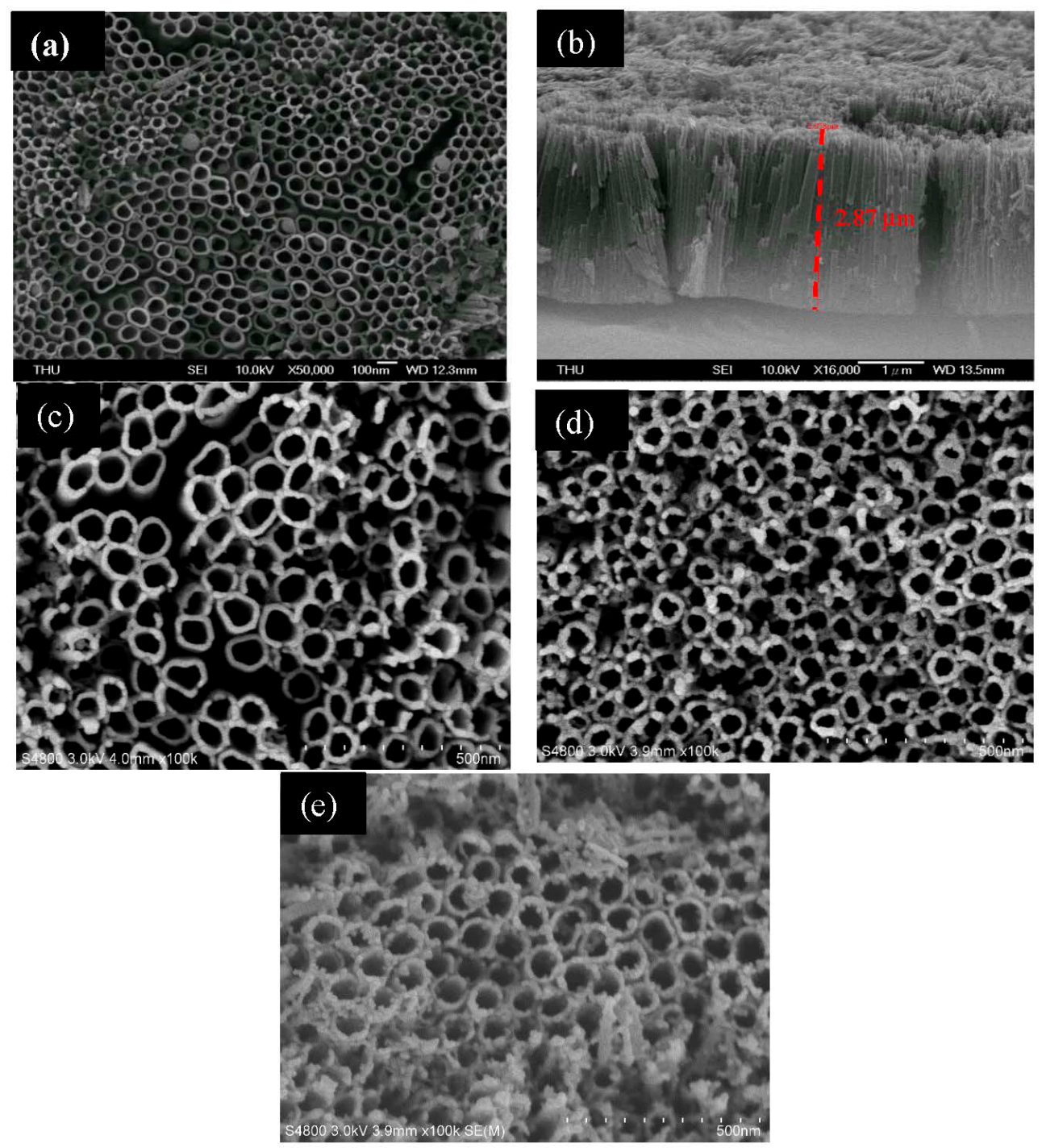

Figure 1. SEM images of (a) titanium dioxide nanotube arrays (TNAs), (b) TNAs (cross section), (c) palladium modified TNAs (Pd/TNAs), (d) Pd/TNAs-C and (e) Pd/TNAs-G.

The formed nano-palladium metal particles are mainly deposited as round nano-particles, and the conditions of different palladium chloride concentrations, dosages and reaction times will affect the deposition effect. Figure 2 shows the X-ray diffraction analysis of TNAs, Pd/TNAs, Pd/TNAs-C and $\mathrm{Pd} / \mathrm{TNAs}-\mathrm{G}$. The standard cards of the Joint Committee for Powder Diffraction Files (JCPDS) were employed for XRD discussion. The TNAs were mainly dominated by $\mathrm{TiO}_{2}$ anatase at $2 \theta$ of $25.3^{\circ}, 37.8^{\circ}$, and $54.0^{\circ}$, corresponding to the crystal planes of (101), (004), and (105), respectively. According to JCPDS 46-1043, ideally, $2 \theta$ will have characteristic peaks of Pd at $40.0^{\circ}, 46.7^{\circ}, 68.0^{\circ}, 82.0^{\circ}$, and $86.5^{\circ}$. The results are similar to those of El-Rady et al. [25], illustrating that palladium NPs are successfully dispersed in the $\mathrm{TiO}_{2}$ substrate. 


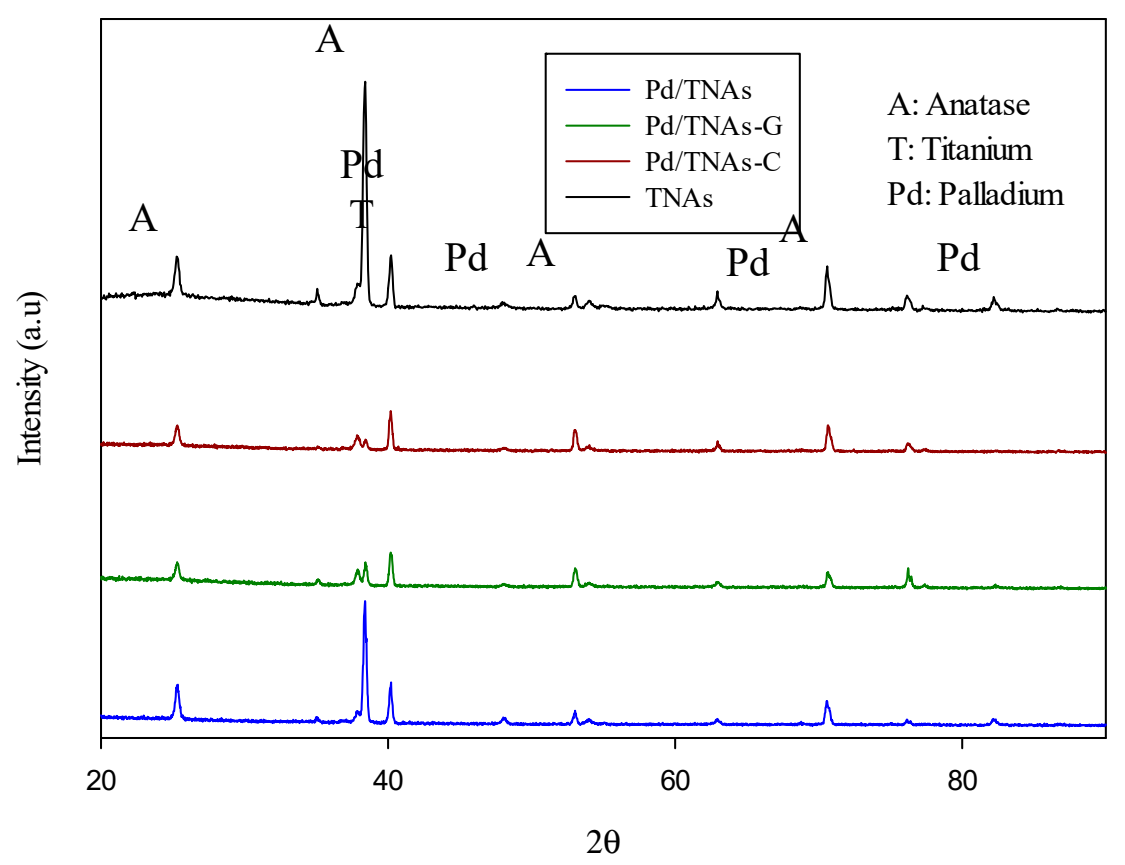

Figure 2. XRD analysis of TNAs, Pd/TNAs, Pd/TNAs-C, and Pd/TNAs-G.

Figure 3 shows the results of XPS analysis for Pd/TNAs-C (The results of XPS analysis for $\mathrm{Pd} / \mathrm{TNAs}-\mathrm{G}$ and Pd/TNAs are shown in Supporting Information as Figures $\mathrm{S} 1$ and S2). Figure 3a shows peaks at 284.6 and $286.5 \mathrm{eV}$ that were attributed to element carbon and $\mathrm{C}-\mathrm{O}$ bands. Figure $3 \mathrm{~b}$ shows that the Ti spectrum includes two characteristic peaks at $458.8 \mathrm{eV}$ and $464.3 \mathrm{eV}$, corresponding to element states of Ti $2 p_{3 / 2}$ and Ti $2 p_{1 / 2}$, respectively. The peak in the Ti $2 p$ region demonstrates that Ti exists in $\mathrm{Ti}^{4+}$, as confirmed by the oxidation of $\mathrm{Ti}^{2}$ to $\mathrm{TiO}_{2}$. Figure $3 \mathrm{c}$ shows the $\mathrm{O} 1 \mathrm{~s}$ spectra, which includes two characteristic peaks at $530.0 \mathrm{eV}$ and $532.8 \mathrm{eV}$, which are assigned to the Ti-O bonds in $\mathrm{TiO}_{2}$ [26]. The Pd spectra (Figure 3d) include four clear peaks at 335.1, 337.8, 340.5, and $342.7 \mathrm{eV}$. The Pd $3 \mathrm{~d}_{5 / 2}$ peaks at about $335.1 \mathrm{eV}$ and the $\mathrm{Pd} 3 \mathrm{~d}_{3 / 2}$ peaking near $340.5 \mathrm{eV}$, are represented as $\mathrm{Pd}^{0}$, while the $\mathrm{Pd}$ $3 \mathrm{~d}_{5 / 2}$ peaking at $337.8 \mathrm{eV}$ and $\mathrm{Pd} 3 \mathrm{~d}_{3 / 2}$ peaking at $342.7 \mathrm{eV}$ are represented as $\mathrm{PdO}$ [27]. Table 1 shows the XPS analysis results of $\mathrm{Pd} / \mathrm{TNAs}-\mathrm{C}$, revealing that the atomic percentages for $\mathrm{C}, \mathrm{O}$, Ti, and $\mathrm{Pd}$ were $58.30 \%, 34.60 \%, 5.97 \%$, and $1.13 \%$, respectively. Notably, the Pd occupied $0.82 \%, 1.13 \%$, and $1.08 \%$ of $\mathrm{Pd} / \mathrm{TNAs}, \mathrm{Pd} / \mathrm{TNAs}-\mathrm{C}$, and Pd/TNAs-G, respectively. From the XPS results, we can confirm that Pd was successfully deposited on the surface of TNAs by the microwave hydrothermal method.

Figure 4 shows the UV-VIS absorption spectra for TNAs, Pd/TNAs, Pd/TNAs-C, and Pd/TNAs-G. The absorption of TNAs mainly falls in the range of $383 \mathrm{~nm}\left(E_{g}=3.2 \mathrm{eV}\right)$, which corresponds to the anatase phase of $\mathrm{TiO}_{2}$. TNAs were successfully synthesized by doping Pd with the microwave hydrothermal method to form Pd/TNAs. The absorption of Pd/TNAs red-shifts to the visible light region at about $414 \mathrm{~nm}\left(E_{g}=2.95 \mathrm{eV}\right)$. The light response of the as-synthesized material was enhanced by adding the reducing agent (tea, coffee) during the microwave hydrothermal method, as evidenced by the Pd/TNAs-C $\left(474 \mathrm{~nm}\right.$, i.e., $\left.E_{g}=2.37 \mathrm{eV}\right)$ and Pd/TNAs-G $\left(441 \mathrm{~nm}\right.$, i.e., $\left.E_{g}=2.75 \mathrm{eV}\right)$ performing higher light absorptions than the TNAs and Pd/TNAs.

Table 1. The percentage of each element by XPS analysis of Pd/TNAs, Pd/TNAs-C and Pd/TNAs-G.

\begin{tabular}{cccccc}
\hline Elements & C (Atomic \%) & O (Atomic \%) & Ti (Atomic \%) & Pd (Atomic \%) & Total \\
\hline Pd/TNAs & 59.75 & 34.18 & 5.25 & 0.82 & 100.00 \\
Pd/TNAs-C & 58.30 & 34.60 & 5.97 & 1.13 & 100.00 \\
Pd/TNAs-G & 66.21 & 29.42 & 3.28 & 1.08 & 100.00 \\
\hline
\end{tabular}



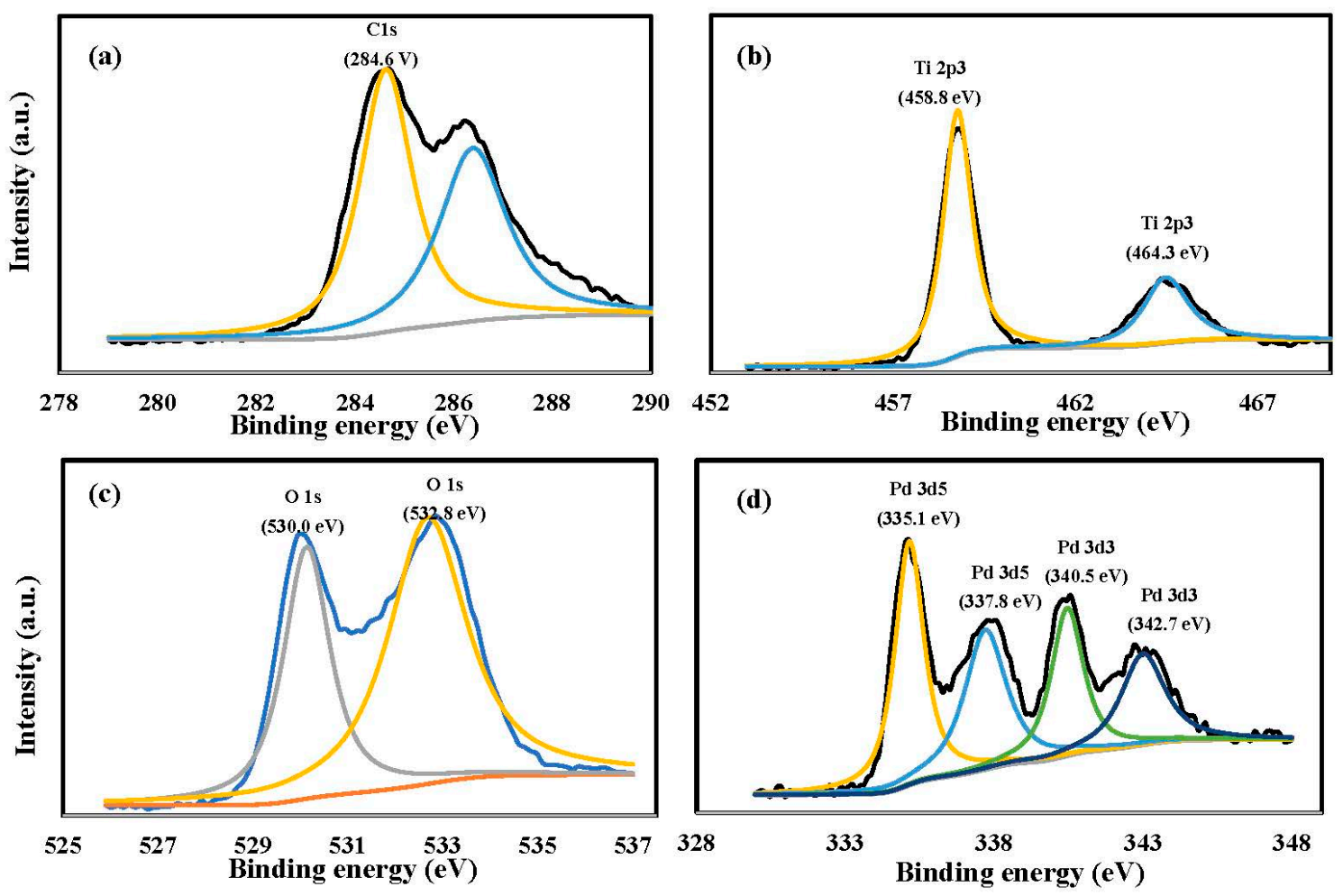

Figure 3. XPS analysis of Pd/TNAs-C (a) C 1s, (b) Ti 2p, (c) O 1s, and (d) Pd 3d5 3d3.

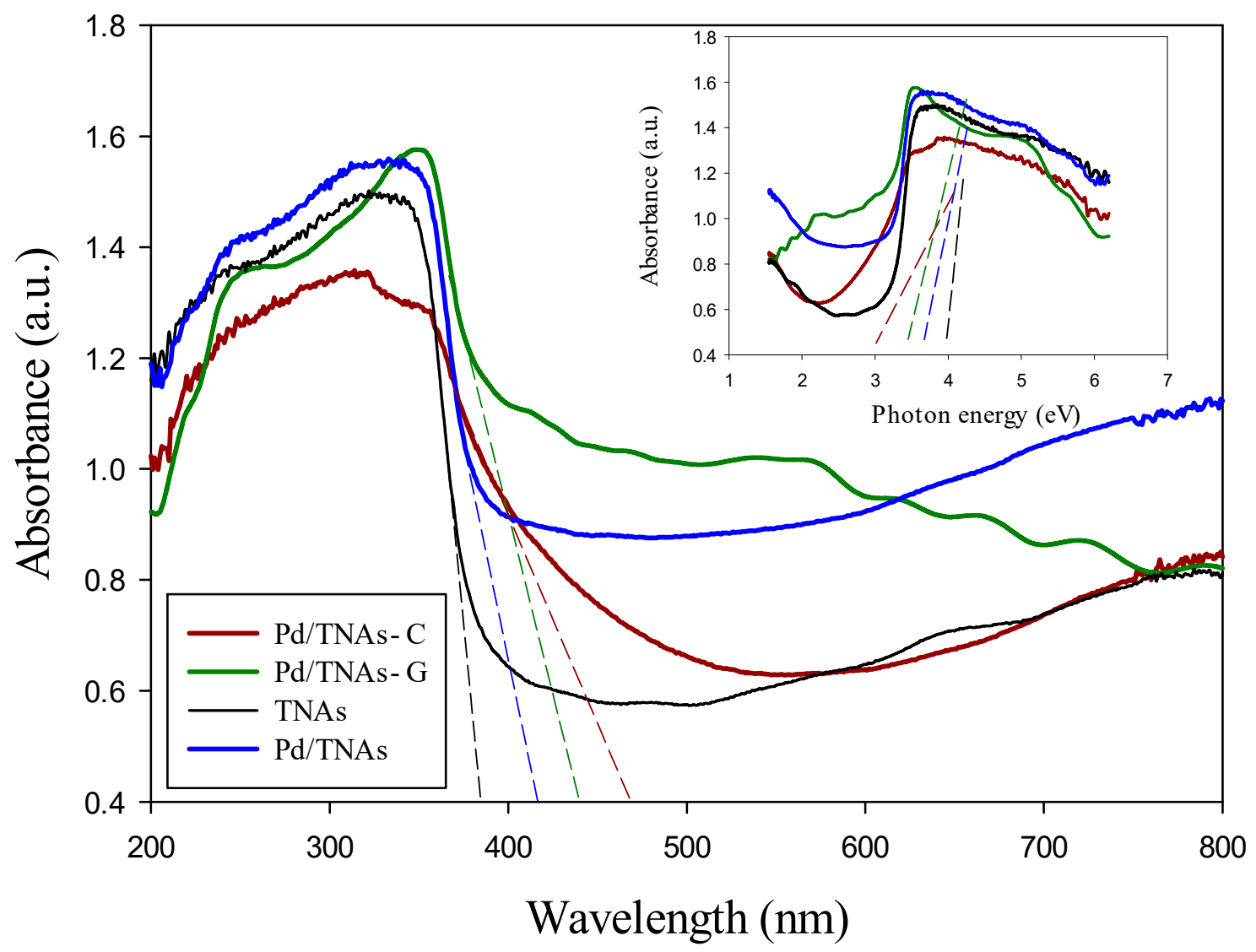

Figure 4. UV-VIS spectra of TNAs, Pd/TNAs, Pd/TNAs-C, and Pd/TNAs-G. 


\subsection{Electrochemical Performance}

Figure 5 shows the photo-current-time response for TNAs, Pd/TNAs, Pd/TNAs-C, and Pd/TNAs-G under light (100 W mercury lamp) at $+1.0 \mathrm{~V}$ (vs. Ag/AgCl). From Figure 5, when the light is on, the photo-generated currents are 1.5, 3.1, 4.0, and $3.7 \mathrm{~mA} / \mathrm{cm}^{2}$ for TNAs, Pd/TNAs, Pd/TNAs-C, and Pd/TNAs-G, respectively. The photo-currents of Pd/TNAs, Pd/TNAs-G, and Pd/TNAs-C are 2.00, 2.47, and 2.67 times higher than that of pure TNAs, respectively. This result confirms the UV-VIS findings, that depositing Pd on TNAs can enhance the photo-response of TNAs, leading to the generation of a photocurrent.

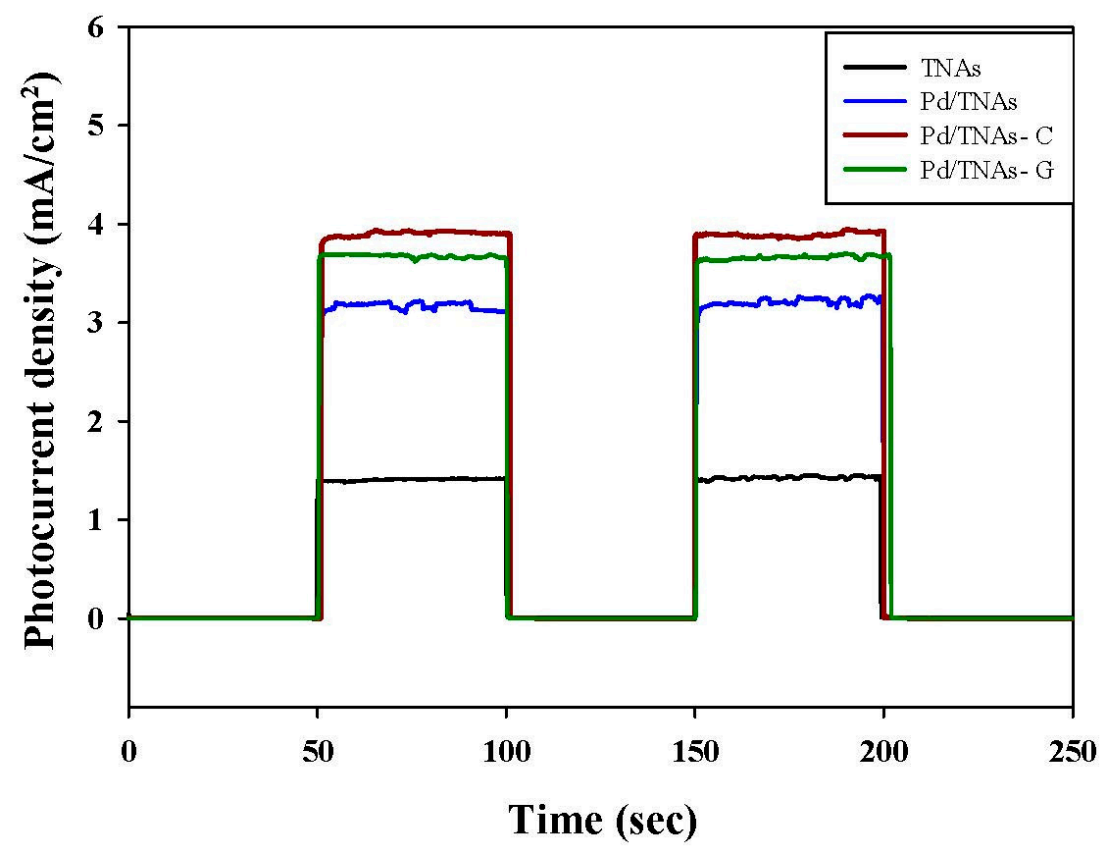

Figure 5. I-t graph of each material by switching lamp test under $100 \mathrm{~W}$ Hg lamp illuminations.

The behavior of charge transfer and recombination at the semiconductor-electrolyte interface can be studied by EIS. Figure 6 shows the Nyquist plots for TNAs, Pd/TNAs, Pd/TNAs-C, and Pd/TNAs-G electrodes (fitting parameters are shown in Figure S2 in supplementary information). According to the literature, a smaller semi-circular arc diameter means a faster transfer of interfacial charge to an electron donor-acceptor or photo-generated electron-hole, thereby enabling more efficient separation [28]. The radii follow the order of TNAs $>\mathrm{Pd} / \mathrm{TNAs}>\mathrm{Pd} / \mathrm{TNAs}-\mathrm{C}>\mathrm{Pd} / \mathrm{TNAs}-\mathrm{G}$. Electrochemical analysis results can clearly prove that $\mathrm{Pd} / \mathrm{TNAs}, \mathrm{Pd} / \mathrm{TNAs}-\mathrm{C}$ and $\mathrm{Pd} / \mathrm{TNAs}-\mathrm{G}$ electrodes have a smaller charge transfer resistance than TNA electrodes. Pd/TNAs-G and Pd/TNAs-C electrodes with tea and coffee as reducing agents can reduce electrode impedance to 1.5 times that of TNAs. Table 2 summarizes the impedance of the tested electrodes, where $R_{S}$ represents the resistance of the solution; $R_{p}$ represents the resistance to charge transfer at the interface between $\mathrm{Cu}_{2} \mathrm{O}$ /TNAs and electrolytes, and CPE represents the constant phase element. From Table 2, the $R_{p}$ values were 112.72 and $108.93 \Omega$ for Pd/TNAs-C and $\mathrm{Pd} / \mathrm{TNAs}-\mathrm{G}$, respectively, which are significantly smaller than that of TNAs $(384.25 \Omega)$. The $R_{p}$ may also vary with the thickness and the crystalline composition for the electrode $[29,30]$. Yalavarthi et al. (2019) applied an anatase and rutile mixed-phase $\mathrm{TiO}_{2}$ for PEC water splitting and found that the $R_{p}$ was the smallest at the anatase-to-rutile ratio of 82:18. On the other hand, Gimenez et al. (2012) used mesoporous $\mathrm{TiO}_{2}$ for water splitting and indicated that the $\mathrm{R}_{\mathrm{p}}$ was reduced with the increasing thickness of the mesoporous $\mathrm{TiO}_{2}$ electrode. In this study, we investigated the electron lifetime $\tau_{e l}$ of the photoexcited electrons in the PEC system. Figure 7 shows the Bode plot in the range of $10^{-2}-10^{2} \mathrm{~Hz}$. Results show that the peak values are 0.72 and $0.96 \mathrm{~Hz}$ for Pd/TNAs-C and Pd/TNAs-G, respectively. As shown in Table 3, according to the formula, $\tau_{\mathrm{el}}=1 /(2 \pi \mathrm{fmax})$, the electron lifetimes are $221.2 \mathrm{~ms}$ and 
$165.9 \mathrm{~ms}$ for Pd/TNAs-C and Pd/TNAs-G, respectively. Similar results can also be found in the study by Chang et al. (2016), who showed that the $\tau_{\mathrm{el}}$ was $13.28 \mathrm{~ms}$ for pure TNAs under electrochemical anodizing for synthesis [31].

Table 2. The fitting result of TNAs, Pd/TNAs, Pd/TNAs-C and Pd/TNAs-G.

\begin{tabular}{cccc}
\hline- & $\boldsymbol{R} \boldsymbol{s}^{\mathbf{a}}(\boldsymbol{\Omega})$ & $\boldsymbol{R} \boldsymbol{p}^{\mathbf{b}} \mathbf{n}(\boldsymbol{\Omega})$ & $\boldsymbol{C P E ^ { \mathbf { c } } ( \boldsymbol { \Omega } )}$ \\
\hline TNAs & 28.12 & 384.25 & 0.0048 \\
Pd/TNAs & 37.79 & 340.96 & 0.0034 \\
Pd/TNAs-C & 24.64 & 112.72 & 0.0035 \\
Pd/TNAs-G & 25.80 & 108.93 & 0.0057 \\
\hline
\end{tabular}

a. $R_{S}$ represents the resistance of the solution; b. $R_{p}$ represents the resistance to charge transfer at the interface between $\mathrm{Cu}_{2} \mathrm{O} / \mathrm{TNAs}$ and electrolytes, c. CPE represents the constant phase element.

Table 3. The electronic life of Pd/TNAs-C and Pd/TNAs-G.

\begin{tabular}{ccc}
\hline- & $f_{\text {max }}(\mathbf{H z})$ & $\tau_{t}(\mathbf{m s})$ \\
\hline Pd/TNAs-C & 0.72 & 221.2 \\
Pd/TNAs-G & 0.96 & 165.9 \\
\hline
\end{tabular}

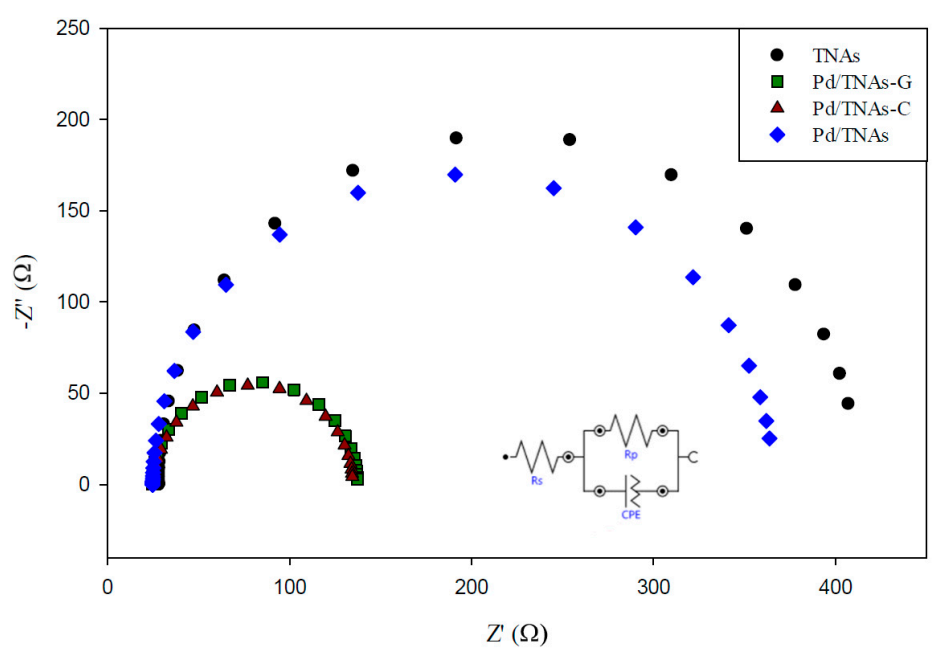

Figure 6. Nyquist graph of TNAs, Pd/TNAs, Pd/TNAs-C, and Pd/TNAs-G under $100 \mathrm{~W}$ Hg lamp.

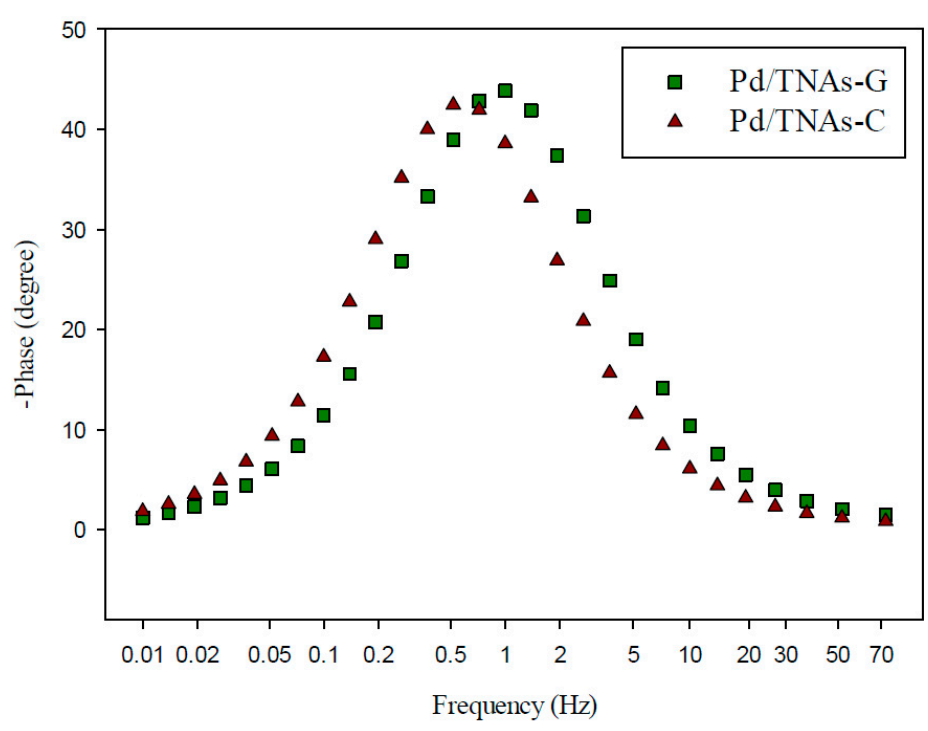

Figure 7. Bode plot of Pd/TNAs-C and Pd/TNAs-G under $100 \mathrm{~W}$ Hg lamp. 


\subsection{MO Degradation via the Pd/TNAs PEC System}

In this study, methyl orange was used as the target pollutant to evaluate the degradation ability of TNAs, Pd/TNAs, Pd/TNAs-C, and Pd/TNAs-G. The photoelectrochemical, photocatalytic, photolysis and electrochemical methods were compared for MO degradation. The initial concentration of MO was $10 \mathrm{ppm}$ in $0.1 \mathrm{M} \mathrm{NaCl}$ solution. In the PEC, PC, and P systems, the light source was a $100 \mathrm{~W} \mathrm{Hg}$ lamp. The bias potential was $+1.0 \mathrm{~V}$ (vs. $\mathrm{Ag} / \mathrm{AgCl}$ ) in the PEC and EC (electrochemical) system. Figure $8 \mathrm{a}-\mathrm{d}$ compares different methods for degrading MO by using TNAs as photo-anodes. Among the four methods, the MO removal efficiency follows the order of PEC $>$ PC $>$ EC $>$ P. PCE is the most efficient way to remove MO. From Figure 8, it seems that MO is rarely degraded by electrochemical oxidation and photolysis. This observation is similar to that of Peng et al. (2012), who applied an N-doped $\mathrm{TiO}_{2}$ thin film as a photoanode in a PEC system to remove MO [32]. Photocatalytic oxidation of MO was effective for TNAs, Pd/TNAs, Pd/TNAs-C, and Pd/TNAs-G. With light illuminating the photocatalysts (i.e., TNAs), photo-generated electrons can jump from a valence band to the conduction band and leave photo-generated holes to react with water molecules, and thus generate hydroxyl radicals $(\cdot \mathrm{OH})$. The $\cdot \mathrm{OH}$ is one of the strong oxidantants which can degrade $\mathrm{MO}$ easily. However, the recombination of photo-generated electrons and holes may decrease the efficiency of MO degradation. Notably, MO can be completely removed in 2, 1, 0.5, and $1 \mathrm{~h}$, with a rate constant of $2.16 \times 10^{-1}, 7.58 \times 10^{-1}$, 1.05 , and $7.91 \times 10^{-1} \mathrm{~h}^{-1}$, in TNAs, Pd/TNAs, Pd/TNAs-C, and Pd/TNAs-G PEC systems, respectively. In the Pd/TNAs PEC system, with Pd NP modification, the rate constant of MO degradation is 4.86 times higher than that of the pure TNAs. This result illustrates that Pd depositing can reduce the bandgap of TNAs and enhance the light response. Although some researchers proposed that dyes are inappropriate as model systems for the testing of the PC activity of photocatalysts [33], dyes are easy to observe and important sources of water pollutants. Figure 9a shows the results of the total organic carbon (TOC) removal rate of MO PEC degradation by using TNAs, Pd/TNAs, $\mathrm{Pd} / \mathrm{TNAs}-\mathrm{C}$, and Pd/TNAs-G. Similar to MO degradation, PEC performs the most efficiently to remove the TOC of MO. In a $4 \mathrm{~h}$ PEC reaction time, the TOC removal rates reached 32\%, 39\%, 55\%, and 51\% by using TNAs, Pd/TNAs, Pd/TNAs-C, and Pd/TNAs-G, respectively. Similar results are found by Hernández-Gordillo et al. (2019), who used $\mathrm{Bi}_{2} \mathrm{O}_{3}$ to degrade rhodamine- $\mathrm{B}(\mathrm{RhB})$, acid blue $113(\mathrm{AB})$ and indigo carmine (IC). The TOC removal reached $52 \%, 81 \%$, and $56 \%$ for $\mathrm{RhB}, \mathrm{AB}$ and IC, respectively, indicating that by-products were remaining in the solutions [34]. 
(a)

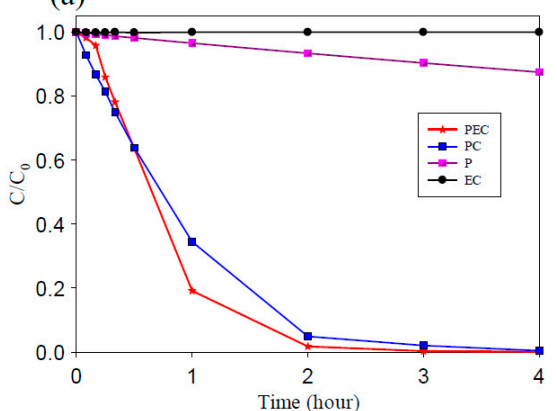

(c)

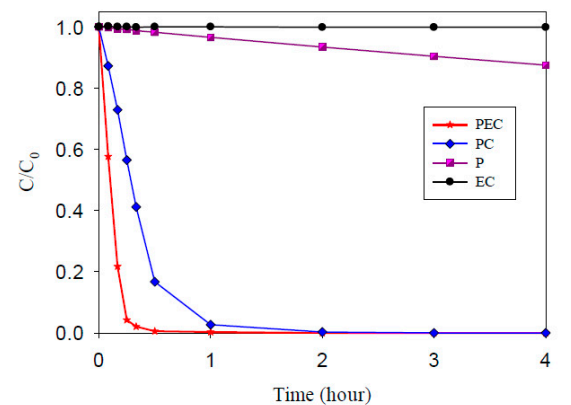

(b)

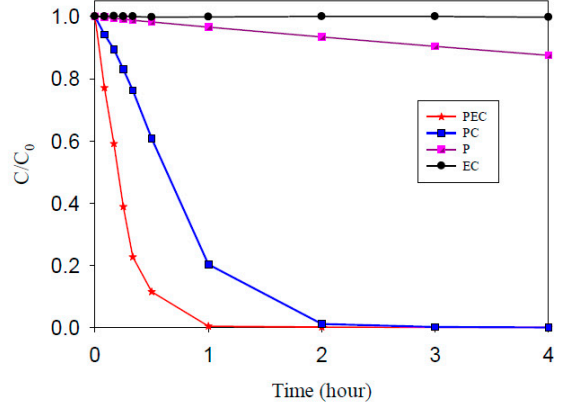

(d)

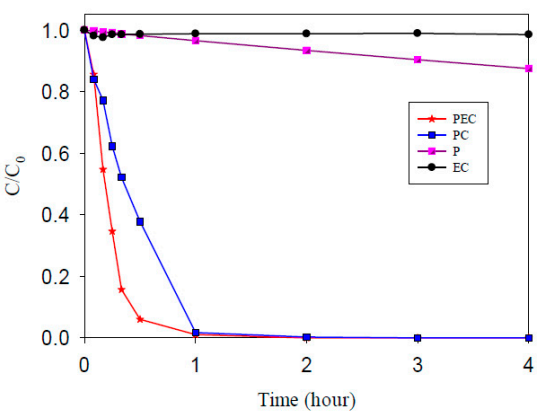

Figure 8. The degradation efficiency of methyl orange (a) TNAs, (b) Pd/TNAs, (c) Pd/TNAs-C, and (d) Pd/TNAs-G.

(a)

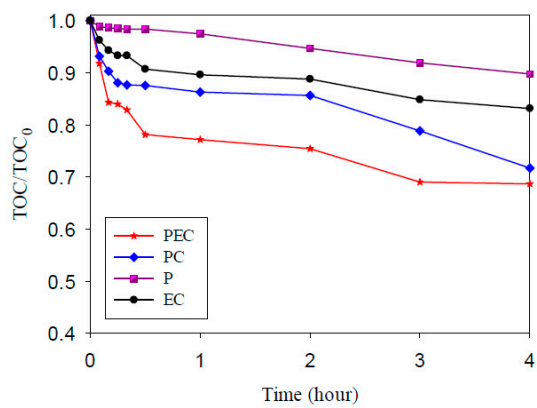

(c)

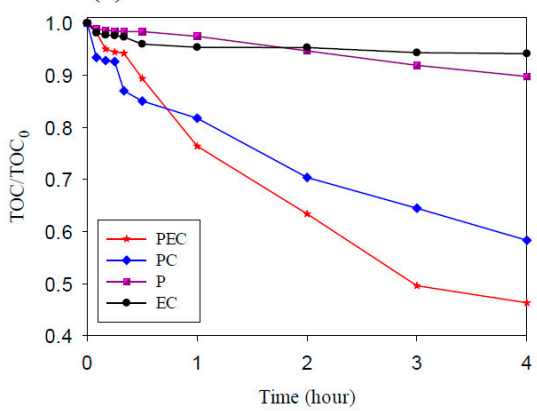

(b)

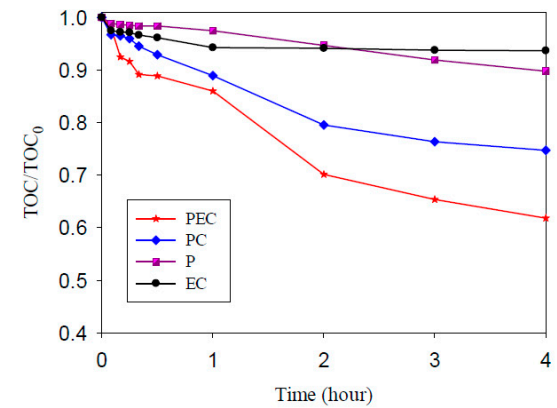

(d)

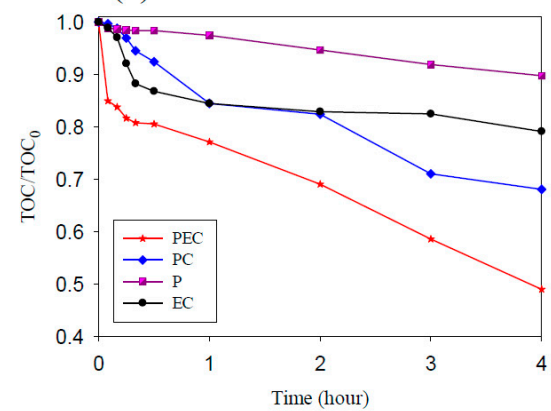

Figure 9. The removal rate of total organic carbon (TOC) by degrading methyl orange (a) TNAs, (b) Pd/TNAs, (c) Pd/TNAs-C, and (d) Pd/TNAs-G. 


\subsection{Hydrogen Generation via the Pd/TNAs PEC System}

In the cathodic chamber, the photo-generated electrons, which are attracted from the anodic chamber, could reduce water to hydrogen. Figure 10 compares the hydrogen production of various materials using PEC methods. Upon $30 \mathrm{~min}$ of reaction, hydrogen-with a concentration of $238.6 \mathrm{mM} / \mathrm{cm}^{2}$ - was observed in the Pd/TNAs-C PEC system, while no hydrogen was yet detected in the TNAs, Pd/TNAs, and Pd/TNAs-G PEC systems. In the fourth hour, hydrogen production of TNAs, $\mathrm{Pd} / \mathrm{TNAs}$, Pd/TNAs-C, and Pd/TNAs-G was 560.1, 838.8, 1677.9 , and $1273.3 \mathrm{mM} / \mathrm{cm}^{2}$, respectively. In general, the trends of hydrogen generation in the cathodic chamber are consistent with the results of photocurrent-time responses (Figure 5).

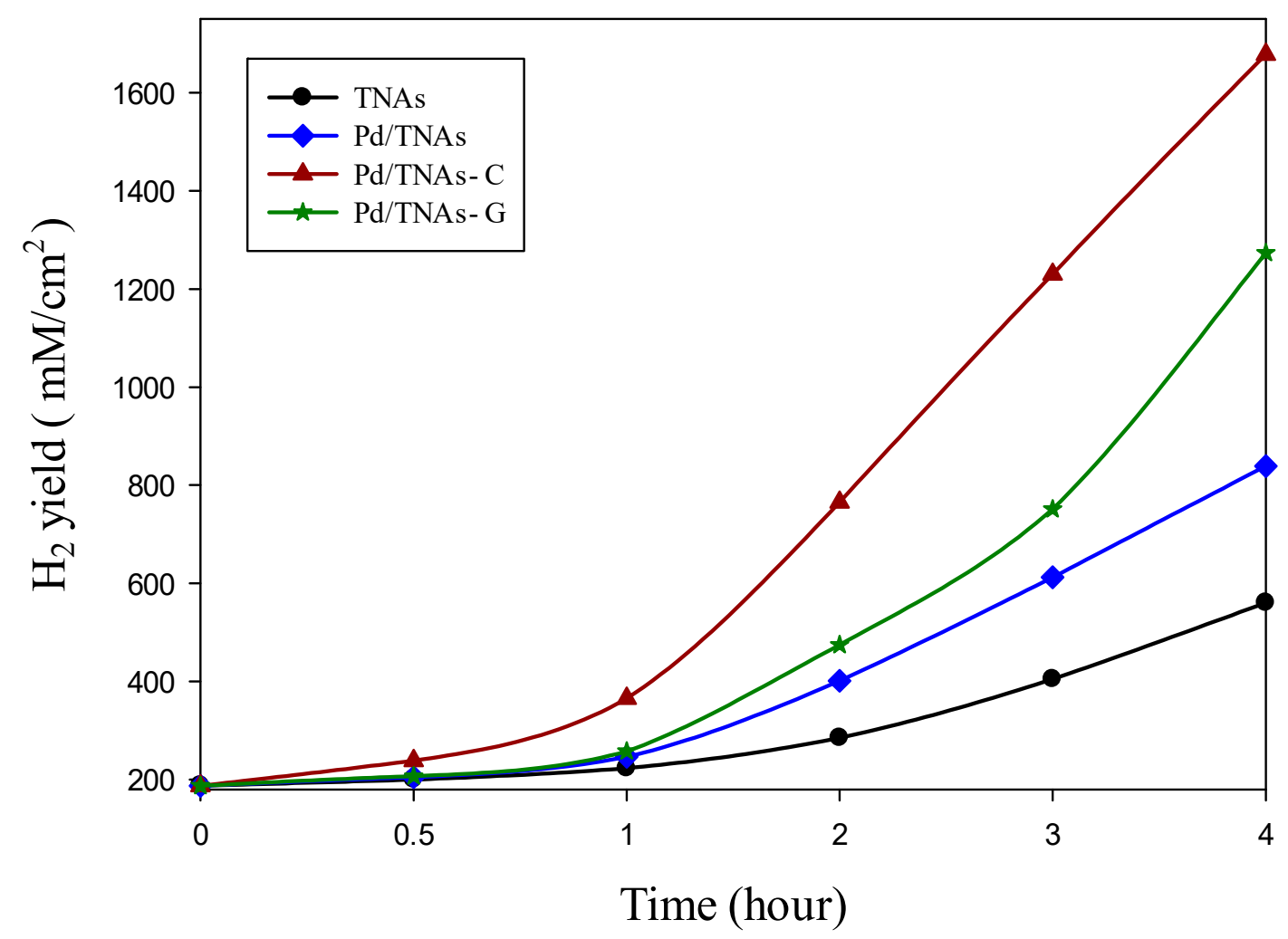

Figure 10. Comparison of hydrogen production by each material via the photoelectrochemical method.

\subsection{Durable Test for Pd/TNAs}

The durability test of the Pd/TNAs-C PEC degradation of MO, as well as hydrogen generation were also performed. As shown in Figure 11, the Pd/TNAs-C PEC removal of MO showed good stability during PEC cycle and retained $100 \%$ of its initial activity, with the first-pseudo rate constants of $0.0174,0.0165,0.052 \mathrm{~min}^{-1}$ for three runs. Meanwhile, TOC removal in triplicate experiments all reached $50 \%$, with rate constants of $0.0034,0.0032$ and $0.0027 \mathrm{~min}^{-1}$. In addition, in the cathodic chamber, the concentration of hydrogen generation was 1677,1605 and $1593 \mu \mathrm{M} / \mathrm{cm}^{2}$ after $4 \mathrm{~h}$ of reaction time for each cycle. The results above illustrate that $\mathrm{Pd} / \mathrm{TNAs}-\mathrm{C}$ exhibits high stability and can be reused. 
(a)

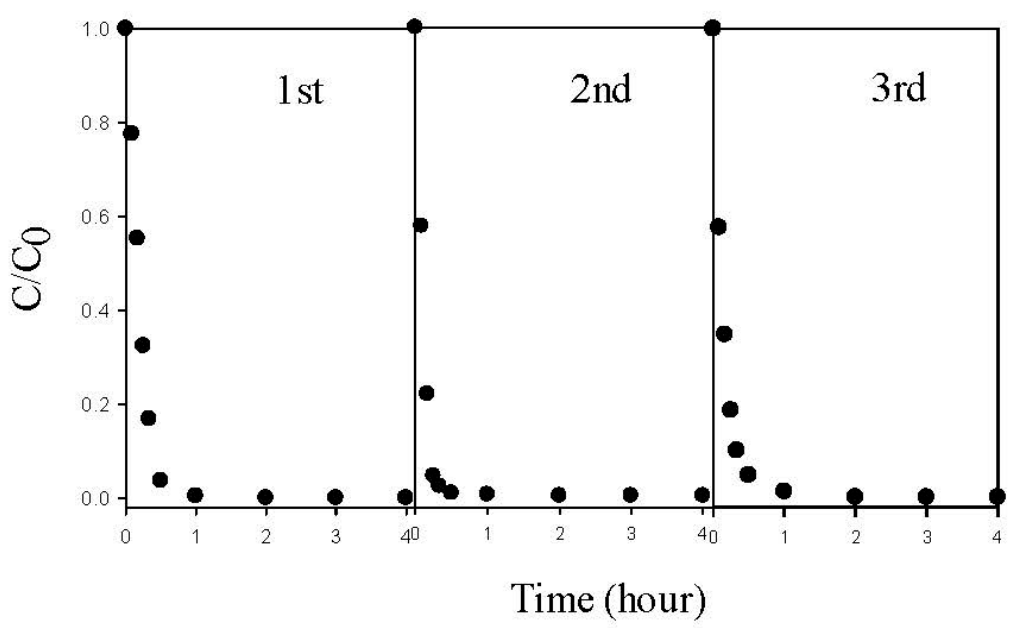

(b)

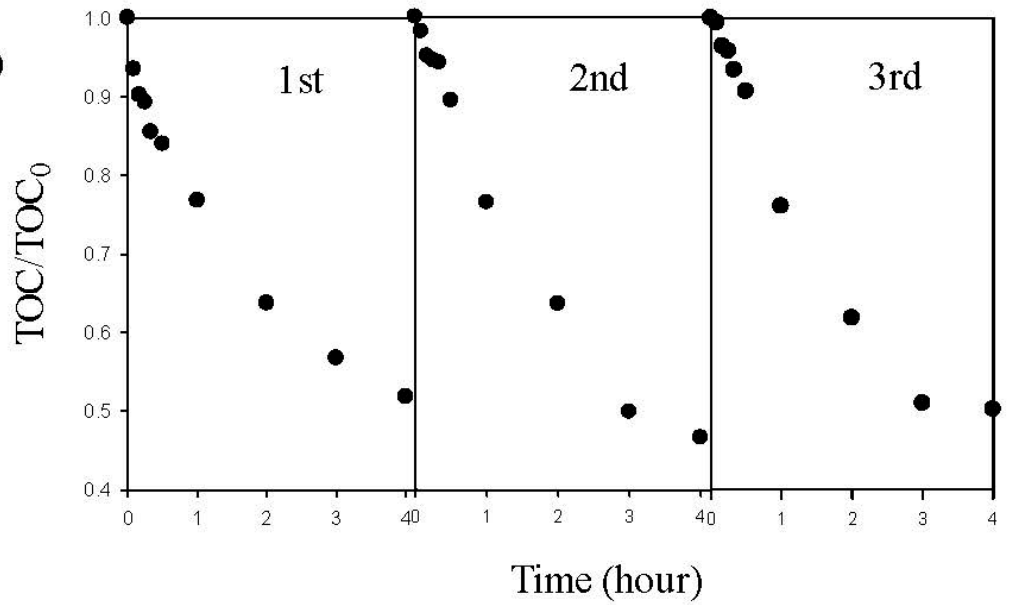

(c)

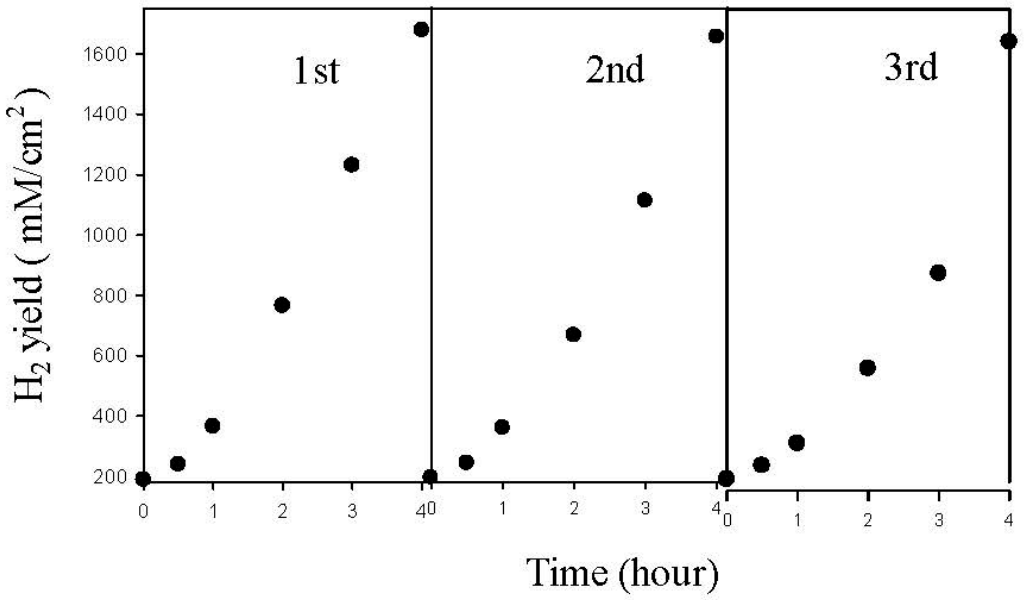

Figure 11. The repeated experiment by $\mathrm{Pd} / \mathrm{TNAs}-\mathrm{C}$ in photoelectrochemical (PEC) system (a) methyl orange degradation, (b) total organic carbon removal, and (c) hydrogen production.

\subsection{ESR Analysis}

Figure 12 shows the results of ESR (electron spin resonance) analyses for TNA and Pd/TNAs. As seen in Figure 12a, a peak intensity of 1:2:2:1 was observed after irradiation, indicating the continuous generation of DMPO-OH. Figure $12 \mathrm{~b}$ shows the results of ESR analyses for Pd/TNAs, where hydroxyl radicals were also observed upon light irradiation. The hole-electron pair generated under light illumination and produced applied bias potential promoted valence band electrons $\left(\mathrm{e}_{\mathrm{VB}}\right)$ at 
the conduction band, which yielded valance band holes $\left(\mathrm{h}_{\mathrm{VB}}\right)$ and produced hydroxyl radicals at the surface of photoanode. The latter process is related to the PEC degradation of the pollutant.
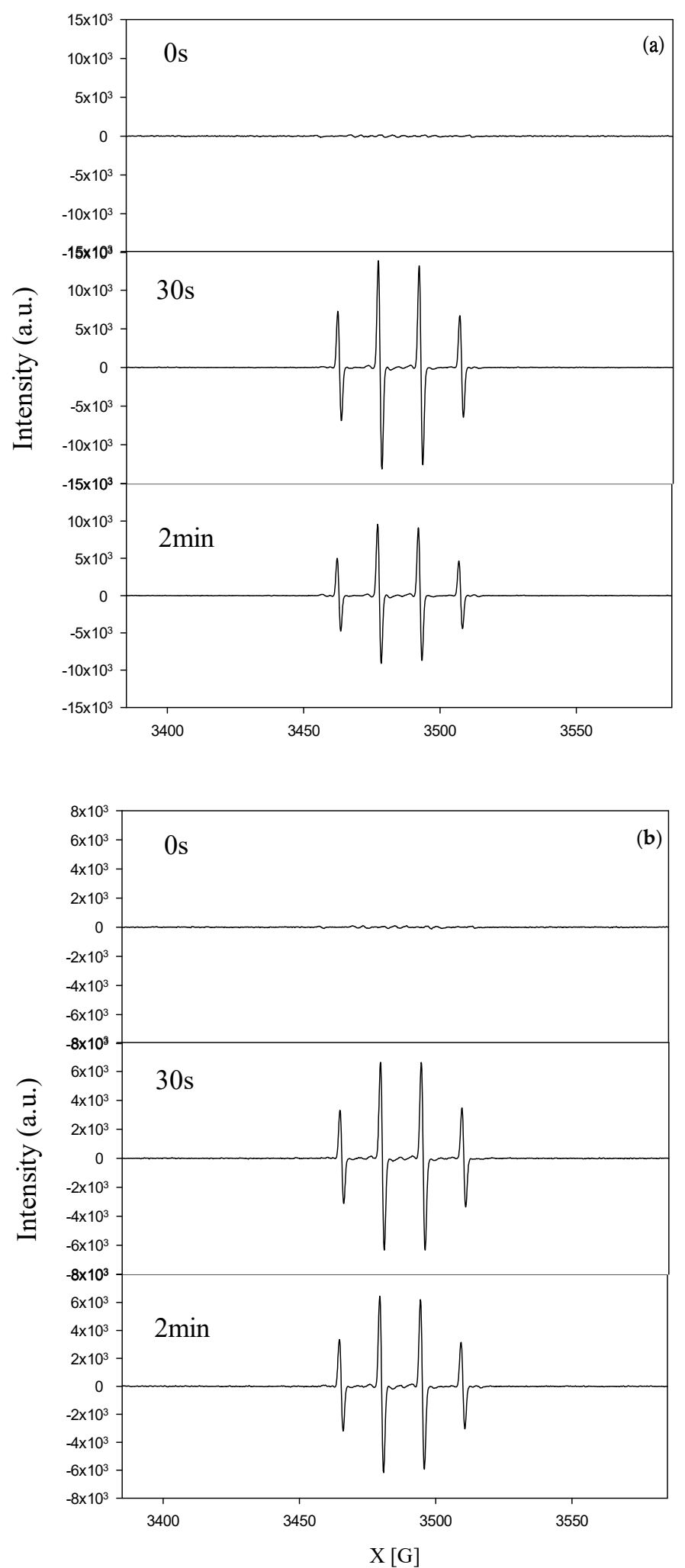

Figure 12. Electron paramagnetic resonance (EPR) signal of DMPO-OH compound under dark reaction and ultraviolet irradiation (a) TNAs and (b) Pd/TNAs. 


\section{Experimental Section}

\subsection{Synthesis of TNAs and Pd/TNAs}

TNAs were prepared by electrochemical anodization, similar to the method described by Peng et al. [35]. Briefly, before anodization, Ti foil $(0.25 \mathrm{~mm}$ thick, $99.5 \%$ purity, Sigma-Aldrich, St. Louis, MI, USA) was cleaned by sonication in 1:1 volume ratio of acetone and ethanol, followed by rinsing with DI water (deionized water) and drying in a stream of air. The cleaned $\mathrm{Ti}$ foil and $\mathrm{Pt}$ were used as anode and cathode, respectively, and placed at a distance of $5.0 \mathrm{~cm}$ from each other in a glass reactor. We then immersed them in ethylene glycol solution ( $99.8 \%$, Sigma-Aldrich) containing $0.25 \mathrm{wt} \% \mathrm{NH}_{4} \mathrm{~F}\left(98.0 \%\right.$, Sigma-Aldrich) and $2 \mathrm{vol} \% \mathrm{H}_{2} \mathrm{O}$. A DC power supply with a constant voltage of $40 \mathrm{~V}$ was used to anodize the Ti foil at room temperature for $1 \mathrm{~h}$. All the obtained TNAs, initially amorphous, were annealed at $450{ }^{\circ} \mathrm{C}$ for $3 \mathrm{~h}$ in the air atmosphere to increase crystallinity.

The Pd-deposited TNAs were synthesized by the microwave-hydrothermal method. First, TNAs were immersed in a solution of $0.1 \mathrm{M} \mathrm{PdCl}_{2}$ (purity $>99.9 \%$, Sigma-Aldrich Co., Ltd.) with a volume of $50 \mathrm{~mL}$, and subjected to microwave heating at $90^{\circ} \mathrm{C}$ for $5 \mathrm{~min}$ under the power of $400 \mathrm{~W}$. Green syntheses of Pd/TNAs were conducted by applying tea leaves and coffee powders as green reductants. Briefly, tea leaves $(8 \mathrm{~g})$ were brewed in $200 \mathrm{~mL}$ of boiled water for $5 \mathrm{~min}$ followed by filtration through a $0.22 \mu \mathrm{m}$ filter to collect the tea solution. Another method of green synthesis of Pd/TNAs-C was conducted using coffee powder. Three grams of coffee powders was brewed in $50 \mathrm{~mL}$ of boiled water for $5 \mathrm{~min}$. The coffee solution was collected by filtration through a $0.22 \mu \mathrm{m}$ filter. $\mathrm{Pd} / \mathrm{TNAs}-\mathrm{C}$ and $\mathrm{Pd} / \mathrm{TNAs}-\mathrm{G}$ were synthesized with the same procedure but replacing the DI water with coffee and green tea solution, respectively.

\subsection{Characterization of Pd-TNAs}

The crystal structure of TNA was analyzed by X-ray diffraction (XRD) (D8 discover SSS, Bruker, Germany) with a $\mathrm{Cu} \mathrm{K} \alpha$ source with a wavelength of $0.154 \mathrm{~nm}$. The JCPDS PDF card database was employed as a reference to identify the XRD peak. A field-emission scanning electron microscope (FE-SEM) (S-4800, Hitachi, Japan) was applied to observe the morphology of as-synthesized materials. The UV-VIS absorption spectra were measured under the diffused reflection mode using the integrating sphere attached to a Jasco T-60 UV-VIS spectrometer. The XPS analyses were conducted on the TNAs with a PHI 5000 Versa Probe system (Physical Electronics, Chanhassen MN, USA). The binding energy of the XPS spectra was calibrated with reference to the C1s peak $284.8 \mathrm{eV}$.

\subsection{PEC and Electrochemical Measurements}

All PEC experiments were conducted in a self-designed three-electrode system. A Pd-TNA, a platinum wire and an $\mathrm{Ag} / \mathrm{AgCl}$ electrode were selected as the working electrode, counter electrode and reference electrode, respectively. In the PEC, PC (photocatalytic) and P (photolysis) processes, a $100 \mathrm{~W} \mathrm{Hg}$ lamp with a power of $95.5 \mathrm{~mW} / \mathrm{cm}^{2}$ was used as the light source. All methyl orange removal experiments were carried out in a H-type reactor, which was designed to separate the anodic and cathodic chamber for comparison of the $\mathrm{MO}$ (methyl orange) degradation by different methods. A cation-exchanged membrane was used to connect these two chambers to maintain the ion balance in the system. A quartz window $\left(7 \mathrm{~cm}^{2}\right)$, on the side of the anode chamber, was used for efficient optical quality. Upon light irradiation, the reaction solution was sampled to determine the concentration change of MO using a UV-VIS spectrophotometer (T-630). In this study, the MO degradation in the PEC system conforms to a pseudo-first-order reaction, and its kinetics can be represented by the following equation: $\ln \left(C_{0} / C\right)=k t$, where $k$ is the apparent rate constant and $C_{0}$ and $C$ are the initial and reaction concentrations of aqueous MO, respectively. The PC experiment was conducted by applying the same system without external potential. An EC oxidation experiment was performed on the same bias without light irradiation. Electrochemical impedance spectroscopy (EIS) tests were carried out under an open circuit voltage over a frequency range from $10 \mathrm{kHz}$ to $10 \mathrm{MHz}$ with an $\mathrm{AC}$ voltage 
magnitude of $5 \mathrm{mV}$. The I-t curve measurements and PEC degradation experiments were controlled by an electricity workstation (AutoLAB PGSTAT302N, Utrecht, The Netherlands).

\section{Conclusions}

In this study, an anodic oxidation etching method was successfully used to fabricate a titanium dioxide nanotube array. Palladium was successfully synthesized by a green synthesis technology-microwave hydrothermal method with tea and coffee as reductants. According to the SEM results, TNAs have a highly ordered tube structure with an average diameter between $300-400 \mathrm{~nm}$. The length of the tube is between $2-3 \mu \mathrm{m}$. XRD analysis showed that TNAs were dominated by the anatase phase. However, Pd could not be judged due to the absence of characteristic peaks. XPS results indicate that $\mathrm{Ti}$ in $\mathrm{Pd} / \mathrm{TNAs}$ exists as +4 state, while Pd is shown in 0 and +2 states. According to the UV-VIS results, the absorption range of Pd/TNAs red-shifts from $383 \mathrm{~nm}$ to $474 \mathrm{~nm}$. The result of the photocurrent test confirms the UV-VIS findings, that depositing Pd on TNAs can enhance the photo-response of TNAs, leading to the generation of a photocurrent. Hydrogen production experiments can be performed in the cathodic chamber while degrading methyl orange in the anodic chamber. Among the four materials, Pd/TNAs-C and Pd/TNAs-G performed better in MO degradation and hydrogen production than TNAs did. ESR uses a DMPO spin trapping agent to capture short-lived radicals, proving that TNAs and Pd/TNAs both form electrons and holes and generate hydrogen and hydroxyl radicals after irradiation with light. In the current PEC system, most of the electrons were transferred to the cathode, which can reduce the recombination of photogenerated electrons and holes, thereby increasing the photon efficiency.

Supplementary Materials: The following are available online at http://www.mdpi.com/2073-4344/10/11/1330/s1, Figure S1: SEM mapping of Pd/TNAs-C; Table S1: EDS results of Pd/TNAs-C.

Author Contributions: Formal analysis, S.-W.H.; Investigation, C.-E.H. and H.-W.L. (Hsing-Wang Li); Methodology, H.-W.L. (Hsiao-Wu Lai); Project administration, C.-H.C.; Supervision, Y.-C.L. (Yuan-Chung Lin) and K.-S.C.; Writing—original draft, Y.-P.P.; Writing—review \& editing, Y.-C.L. (Yung-Chang Lin). All authors have read and agreed to the published version of the manuscript.

Funding: This research was founded by the Ministry of Science and Technology, Taiwan, under grant number 108-2628-E110-007-MY3.

Acknowledgments: This study was funded by the Ministry of Science and Technology, Taiwan, under Grant No. 108-2628-E-110-007-MY3.

Conflicts of Interest: The authors declare no conflict of interest.

\section{References}

1. Anastas, P.T. Green chemistry and the role of analytical methodology development. Crit. Rev. Anal. Chem. 1999, 29, 167-175. [CrossRef]

2. Batmunkh, M.; Shearer, C.J.; Bat-Erdene, M.; Biggs, M.J.; Shapter, J.G. Single-Walled Carbon Nanotubes Enhance the Efficiency and Stability of Mesoscopic Perovskite Solar Cells. ACS Appl. Mater. Interfaces 2017, 9, 19945-19954. [CrossRef] [PubMed]

3. Chang, K.L.; Sun, Q.; Peng, Y.P.; Lai, S.W.; Sung, M.; Huang, C.Y.; Kuo, H.W.; Sun, J.; Lin, Y.C. Cu글 loaded titanate nanotube arrays for simultaneously photoelectrochemical ibuprofen oxidation and hydrogen generation. Chemosphere 2016, 150, 605-614. [CrossRef] [PubMed]

4. Chen, H.; Peng, Y.P.; Chen, T.Y.; Chen, K.F.; Chang, K.L.; Dang, Z.; Lu, G.N.; He, H. Enhanced photoelectrochemical degradation of Ibuprofen and generation of hydrogen via BiOI-deposited $\mathrm{TiO}_{2}$ nanotube arrays. Sci. Total. Environ. 2018, 633, 1198-1205. [CrossRef]

5. Cronemeyer, D.C. Electrical and optical properties of rutile single crystals. Phys. Rev. 1952, 87, 876. [CrossRef]

6. El-Rady, A.A.A. Characterization and photocatalytic efficiency of palladium doped- $\mathrm{TiO}_{2}$ nanoparticles. Adv. Nanoparticles 2013, 2, 372-377. [CrossRef]

7. Fujishima, A.; Honda, K. Electrochemical photolysis of water at a semiconductor electrode. Nature 1972, 238, 37-38. [CrossRef] 
8. Gimenez, S.; Dunn, H.K.; Rodenas, P.; Fabregat-Santiago, F.; Miralles, S.G.; Barea, E.M.; Trevisan, R.; Guerrero, A.; Bisquert, J. Carrier density and interfacial kinetics of mesoporous $\mathrm{TiO}_{2}$ in aqueous electrolyte determined by impedance spectroscopy. J. Electroanal. Chem. 2012, 668, 119-125. [CrossRef]

9. Habisreutinger, S.N.; Schmidt-Mende, L.; Stolarczyk, J.K. Photocatalytic reduction of $\mathrm{CO}_{2}$ on $\mathrm{TiO}_{2}$ and other semiconductors. Angew. Chem. Int. Ed. Engl. 2013, 52, 7372-7408. [CrossRef]

10. Hanawa, T. A comprehensive review of techniques for biofunctionalization of titanium. J. Periodontal Implant. Sci. 2011, 41, 263-272. [CrossRef]

11. Hariharan, D.; Thangamuniyandi, P.; Selvakumar, P.; Devan, U.; Pugazhendhi, A.; Vasantharaja, R.; Nehru, L. Green approach synthesis of $\mathrm{Pd} @ \mathrm{TiO}_{2}$ nanoparticles: Characterization, visible light active picric acid degradation and anticancer activity. Process. Biochem. 2019, 87, 83-88. [CrossRef]

12. Hernández-Gordillo, A.; Bizarro, M.; Gadhi, T.A.; Martínez, A.; Tagliaferro, A.; Rodil, S.E. Good practices for reporting the photocatalytic evaluation of a visible-light active semiconductor: $\mathrm{Bi}_{2} \mathrm{O}_{3}$, a case study. Catal. Sci. Technol. 2019, 9, 1476-1496. [CrossRef]

13. Jung, K.H.; Seo, J.Y.; Lee, S.; Shin, H.; Park, N.G. Solution-processed $\mathrm{SnO}_{2}$ thin film for a hysteresis-free planar perovskite solar cell with a power conversion efficiency of 19.2\%. J. Mater. Chem. A 2017, 5, 24790-24803. [CrossRef]

14. Kar, A.; Raja, K.; Misra, M. Electrodeposition of hydroxyapatite onto nanotubular $\mathrm{TiO}_{2}$ for implant applications. Surf. Coat. Technol. 2006, 201, 3723-3731. [CrossRef]

15. Koelsch, M.; Cassaignon, S.; Guillemoles, J.F.; Jolivet, J.P. Comparison of optical and electrochemical properties of anatase and brookite $\mathrm{TiO}_{2}$ synthesized by the sol-gel method. Thin Solid Films 2002, 403, 312-319. [CrossRef]

16. Lebaschi, S.; Hekmati, M.; Veisi, H. Green synthesis of palladium nanoparticles mediated by black tea leaves (Camellia sinensis) extract: Catalytic activity in the reduction of 4-nitrophenol and Suzuki-Miyaura coupling reaction under ligand-free conditions. J. Colloid Interface Sci. 2017, 485, 223-231. [CrossRef] [PubMed]

17. Lu, L.W.; Peng, Y.P.; Chang, C.N. Applying an activated carbon/silver catalyst to the decomposition of the aqueous solutions of tetramethyl ammonium hydroxide. J. Taiwan Inst. Chem. Eng. 2018, 88, 130-136. [CrossRef]

18. Lu, L.W.; Peng, Y.P.; Chang, C.N. Catalytic ozonation by palladium-manganese for the decomposition of natural organic matter. Sep. Purif. Technol. 2018, 194, 396-403. [CrossRef]

19. Lu, X.; Wang, G.; Zhai, T.; Yu, M.; Gan, J.; Tong, Y.; Li, Y. Hydrogenated $\mathrm{TiO}_{2}$ nanotube arrays for supercapacitors. Nano Lett. 2012, 12, 1690-1696. [CrossRef]

20. Mayedwa, N.; Mongwaketsi, N.; Khamlich, S.; Kaviyarasu, K.; Matinise, N.; Maaza, M. Green synthesis of nickel oxide, palladium and palladium oxide synthesized via Aspalathus linearis natural extracts: Physical properties \& mechanism of formation. Appl. Surf. Sci. 2018, 446, 266-272.

21. Meriam Suhaimy, S.H.; Lai, C.W.; Tajuddin, H.A.; Samsudin, E.M.; Johan, M.R. Impact of TiO $2 \mathrm{Nanotubes}^{\prime}$ Morphology on the Photocatalytic Degradation of Simazine Pollutant. Materials 2018, 11, 2066. [CrossRef] [PubMed]

22. Nadagouda, M.N.; Varma, R.S. Green synthesis of silver and palladium nanoparticles at room temperature using coffee and tea extract. Green Chem. 2008, 10, 859-862. [CrossRef]

23. Ohtani, B. Preparing articles on photocatalysis-Beyond the illusions, misconceptions, and speculation. Chem. Lett. 2008, 37, 216-229. [CrossRef]

24. Park, J.; Won, S.W.; Mao, J.; Kwak, I.S.; Yun, Y.S. Recovery of Pd (II) from hydrochloric solution using polyallylamine hydrochloride-modified Escherichia coli biomass. J. Hazard. Mater. 2010, 181, 794-800. [CrossRef]

25. Peng, Y.P.; Peng, L.C.; Chen, K.F.; Chen, C.H.; Chang, K.L.; Chen, K.S.; Dang, Z.; Lu, G.N.; Sun, J. Degradation of trichloroethylene by photoelectrochemically activated persulfate. Chemosphere 2020, 254, 126796. [CrossRef]

26. Peng, Y.P.; Yassitepe, E.; Yeh, Y.T.; Ruzybayev, I.; Shah, S.I.; Huang, C. Photoelectrochemical degradation of azo dye over pulsed laser deposited nitrogen-doped $\mathrm{TiO}_{2}$ thin film. Appl. Catal. B Environ. 2012, 125, 465-472. [CrossRef]

27. Rahman, M.; Wei, M.; Xie, F.; Khan, M. Efficient Dye-Sensitized Solar Cells Composed of Nanostructural ZnO Doped with Ti. Catalalysts 2019, 9, 273. [CrossRef]

28. Riboni, F.; Nguyen, N.T.; So, S.; Schmuki, P. Aligned metal oxide nanotube arrays: Key-aspects of anodic $\mathrm{TiO}_{2}$ nanotube formation and properties. Nanoscale Horiz. 2016, 1, 445-466. [CrossRef] 
29. Rochkind, M.; Pasternak, S.; Paz, Y. Using dyes for evaluating photocatalytic properties: A critical review. Molecules 2014, 20, 88-110. [CrossRef]

30. Tang, H.; Prasad, K.; Sanjinès, R.; Schmid, P.; Levy, F. Electrical and optical properties of $\mathrm{TiO}_{2}$ anatase thin films. J. Appl. Phys. 1994, 75, 2042-2047. [CrossRef]

31. Wu, M.C.; Lee, P.H.; Lee, D.L. Enhanced photocatalytic activity of palladium decorated $\mathrm{TiO}_{2}$ nanofibers containing anatase-rutile mixed phase. Int. J. Hydrog. Energy 2015, 40, 4558-4566. [CrossRef]

32. Yalavarthi, R.; Naldoni, A.; Kment, Š.; Mascaretti, L.; Kmentová, H.; Tomanec, O.; Schmuki, P.; Zbořil, R. Radiative and non-radiative recombination pathways in mixed-phase $\mathrm{TiO}_{2}$ nanotubes for $\mathrm{PEC}$ water-splitting. Catalalysts 2019, 9, 204. [CrossRef]

33. Yang, X.; Li, Q.; Wang, H.; Huang, J.; Lin, L.; Wang, W.; Sun, D.; Su, Y.; Opiyo, J.B.; Hong, L. Green synthesis of palladium nanoparticles using broth of Cinnamomum camphora leaf. J. Nanoparticle Res. 2010, 12, 1589-1598. [CrossRef]

34. Ye, M.; Gong, J.; Lai, Y.; Lin, C.; Lin, Z. High-efficiency photoelectrocatalytic hydrogen generation enabled by palladium quantum dots-sensitized $\mathrm{TiO}_{2}$ nanotube arrays. J. Am. Chem. Soc. 2012, 134, 15720-15723. [CrossRef]

35. Peng, Y.P.; Chen, H.; Huang, C. The synergistic effect of photoelectrochemical (PEC) reactions exemplified by concurrent perfluorooctanoic acid (PFOA) degradation and hydrogen generation over carbon and nitrogen codoped $\mathrm{TiO}_{2}$ nanotube arrays (CN-TNTAs) photoelectrode. Appl. Catal. B Environ. 2017, 209, 437-446. [CrossRef]

Publisher's Note: MDPI stays neutral with regard to jurisdictional claims in published maps and institutional affiliations.

(C) 2020 by the authors. Licensee MDPI, Basel, Switzerland. This article is an open access article distributed under the terms and conditions of the Creative Commons Attribution (CC BY) license (http://creativecommons.org/licenses/by/4.0/). 